\title{
Microterritorializações urbanas: questões contemporâneas sobre os sujeitos fumantes e o espaço público
}

\section{Urban micro territorialization: contemporary issues on smokers and public space}

\author{
Camilo Darsie \\ Universidade Federal do Rio Grande do Sul \\ camilods@terra.com.br
}

\begin{abstract}
Resumo: O texto apresentado aqui aborda questões relativas aos impactos socioespaciais ocasionados pelas ações de conscientização e de combate ao fumo que são promovidas contemporaneamente em nível nacional. Assim, considera-se, nessa análise, que as normas comportamentais bem como as leis referentes ao cigarro têm contribuído para que as relações sociais, atreladas ao hábito de fumar e pautadas nas relações de poder, instituam posturas 'cidadãs' de controle e vigilância de não fumantes sobre fumantes. Admite-se, portanto, que essa realidade colabora para a emergência de microterritorializações urbanas ligadas ao ato de fumar, marginais aos territórios de não fumantes, as quais parecem ocorrer como forma de resistência às ações de controle do espaço.
\end{abstract}

Palavras-chave: Sujeito fumante. Relações de poder. Espaço público. Território. Microterritorializações urbanas.

Abstract: The text presented here addresses issues concerning the socio-spatial impacts caused by simultaneous national actions promoted for awareness and the fight against smoking. Thus, this analysis considers that the behavioral norms and laws about smoking have contributed to the social relations regarding smoking and ruled by power relations, establishing "politically correct" positions of control and surveillance of non-smokers over smokers. It is assumed therefore that this situation contributes to the emergence of urban micro territories linked to smoking, bordering the territories of non-smokers, which seem to occur as a form of resistance to efforts to control space.

Keywords: Smokers. Relations of power. Public space. Territory. Urban micro territorialization.

Resumen: El texto presentado aquí se ocupa en abordar cuestiones relativas a los impactos socio espaciales causados por las acciones de concientización y lucha contra el tabaquismo que se promueven a nivel nacional. Por lo tanto, se considera, en este análisis, las normas de comportamiento y las leyes relacionadas con el tabaquismo que han contribuido a las relaciones sociales, relacionadas con el tabaquismo y pautadas en las relaciones de poder, instituyan posturas "ciudadanas" de control y vigilancia de no fumadores sobre fumadores. Se supone, pues, que este hecho contribuye a la emergencia de micro territorializaciones urbanas vinculadas al acto de fumar, marginales de los territorios de los no fumadores, por las cuales parecen ocurrir como una forma de resistencia a las acciones de control de espacio.

Palabras clave: Sujeto fumador. Relaciones de poder. Espacio Público. Território. Micro territorializaciones urbanas. 


\section{INTRODUÇÃO}

É possível argumentar que existem poucos trabalhos nos quais sejam apresentadas discussões que envolvam as relações socioespaciais estabelecidas entre fumantes e não fumantes, especialmente no que se refere às normas sociais relacionadas ao tabagismo enquanto produtoras dessas relações. Sobre as análises que envolvem o tema, pode ser observado que a maior parte da literatura disponível é produzida a partir das pesquisas promovidas pelos campos da Saúde e da Economia. Portanto, tais estudos deixam de considerar, na maioria das vezes, possíveis articulações entre outras questões que lhes envolvem bem como os conhecimentos que constituem os estudos geográficos.

É interessante frisar, antes de prosseguir, que pela perspectiva da Saúde inúmeros trabalhos são produzidos a partir da apresentação e utilização de dados relacionados aos malefícios e adoecimentos que são causados pelo ato de fumar aos fumantes e, também, aos não fumantes que podem ser expostos à fumaça do cigarro. A partir dos estudos produzidos no campo da Economia são discutidas, por exemplo, questões relacionadas à movimentação financeira gerada pela indústria do cigarro, ou seja, são destacados os números relacionados aos investimentos e aos lucros referentes ao comércio, à indústria e à agricultura quando ligados à produção de cigarros e, ainda, aos prejuízos que acometem os sistemas de saúde pública em decorrência de doenças causadas pelo tabagismo.

No entanto, o que se propõe aqui é a apresentação de uma análise relacionada ao tabagismo desenvolvida a partir de uma perspectiva mais 'geográfica' em que discussões sejam desdobradas no sentido de considerar que os discursos de combate ao tabagismo e a restrição ao fumo em diversos locais públicos têm provocado efeitos de ordem espacial e comportamental que contribuem para o surgimento de limites - físicos e identitários - os quais estabelecem condições para a circulação e para a permanência de sujeitos que fumam em determinados espaços e/ou grupos. Isso acaba por ocasionar a emergência de microterritorialidades urbanas associadas ao uso do cigarro e às discussões contemporâneas que o envolvem.

É importante esclarecer, nesse momento, que a análise é desenvolvida a partir das lentes dos Estudos Culturais - campo que será descrito, brevemente, na sequência - como forma de estabelecer aproximações entre a Geografia e outras áreas do conhecimento. Sobre isso é interessante mencionar que, ao menos no Brasil, ainda é relativamente modesto o número de incursões acadêmicas realizadas por geógrafos nesse campo do conhecimento, fato que acaba despertando um interesse especial relacionado às pesquisas que são desenvolvidas a partir dos conhecimentos da Geografia.

Nesse sentido, as normas que influenciam/definem a distribuição dos sujeitos no espaço público urbano e seus efeitos de poder podem ser tomadas como elementos interessantes a serem problematizados a partir dos conhecimentos produzidos na área da Geografia. 


\section{ESTUDOS CULTURAIS E O CIGARRO: QUESTÕES SOBRE ARTEFATOS CULTURAIS, SUJEITOS FUMANTES E DISCURSOS DA SAÚDE}

Os Estudos Culturais são um campo de pesquisa surgido no Reino Unido, na década de 1960 e o seu referencial ideológico foi estabelecido a partir do marxismo. Assim, as primeiras análises produzidas no âmbito desses Estudos foram desenvolvidas no Centre for Contemporary Cultural Studies, em Birminghan, por estudiosos como Stuart Hall, Richard Hoggart, Raymond Williams, entre outros. Tais autores partiram do pressuposto de que toda e qualquer pessoa, participa do processo de geração de cultura. Assim, suas análises consideraram, entre outras coisas, as relações entre as diferentes classes sociais e suas influências na produção de identidades culturais.

Nessa perspectiva, os Estudos Culturais podem ser definidos como um campo em que diferentes áreas interagem com o intuito de estudar diversos aspectos da cultura que envolve a sociedade (ESCOSTEGUY, 2000). Portanto, a distribuição socioespacial de sujeitos fumantes e de sujeitos não fumantes, em espaços públicos, pode ser discutida levando-se em conta a articulação de outras áreas à Geografia como, por exemplo, a Saúde, a Sociologia e a Filosofia. É interessante mencionar que as pesquisas produzidas a partir desse campo apresentam, em geral, versatilidade teórica, espírito reflexivo e, especialmente, consideram a importância da crítica, em seu sentido mais amplo e não apenas negativo (JOHNSON, 2000).

Assim, é necessário entender os Estudos Culturais como uma área que visa produzir conhecimentos que, de certo modo, indiquem as maneiras pelas quais determinados aspectos da cultura têm se desdobrado e produzido significados diversos em determinadas sociedades, sem que, para isso, seja necessário estabelecerem-se diferenciações entre o que é certo/positivo e o que é errado/negativo. Portanto, não se pretende, neste texto, questionar a validade das ações de combate ao fumo, muito menos estabelecer uma posição de contrariedade a essas ações. O objetivo dos desdobramentos apresentados aqui é indicar algumas pistas sobre como se estabelecem normas e comportamentos sociais frente aos conhecimentos e aos discursos relacionados ao tabagismo.

É importante ressaltar, ainda, que a partir dessa lógica, não são buscadas verdades absolutas ou então descobertas definitivas. Na contramão disso, as pesquisas visam relacionar e revisar questões referentes aos objetos de estudo escolhidos pelos pesquisadores abrindo possibilidades de novos questionamentos associados às temáticas abordadas, pois se considera que existem diferentes maneiras de 'olhar'-se para diferentes questões. Portanto, ao ser proposta uma discussão que envolva o cigarro por intermédio dos Estudos Culturais, é importante levar-se em conta que ele não pode ser considerado apenas um produto que causa problemas à saúde ou um vício que precisa ser deixado de lado, mas um artefato cultural que impõe ao seu usuário uma condição, nesse caso, a condição de fumante que pode ser determinante no que se refere, sobretudo, ao acesso e à permanência nos espaços em que tais sujeitos circulam.

Ao definir o conceito de artefato cultural, Du Gay et al. (1997) afirmam que determinados artefatos, como o cigarro, por exemplo, são culturais também porque são 
constituídos por nós como objetos significativos. Pode-se dizer também que ele é cultural por estar ligado a um conjunto particular de práticas sociais, específicas de nossa cultura e de determinados modos de vida. Nessa direção, pode ser afirmado que o cigarro está associado a certos tipos de pessoas, associação que passa por modificações desde seu surgimento. Assim, como consequência dessa tomada do cigarro enquanto um artefato cultural, emergem questões relativas àquelas pessoas que fazem uso de tal artefato, ou seja, os 'sujeitos fumantes'.

Sobre a noção de sujeito, Silva (2000) refere que ele é um efeito proveniente do discurso e das relações de poder. Os discursos contribuem para a constituição de todas as dimensões da estrutura social que, direta ou indiretamente, o moldam e o restringem com base em suas próprias normas e convenções e das relações, identidades e instituições que lhe são subjacentes. (FAIRCLOUGH, 2001). O discurso é uma prática, não apenas de representação do mundo, mas sobretudo de significação do mundo, constituindo-o e reconstituindo-o em significado.

Assim, o discurso, ao mesmo tempo em que trata dos sujeitos também os constitui como sujeitos desse discurso, os quais acabam por colocá-lo novamente em circulação - tal como afirma Hall (2003), os discursos constituem os sujeitos e os tornam seus divulgadores por intermédio da interpelação. Aqui, portanto, é necessário se chamar a atenção para o fato de que ao ser usada a denominação 'sujeito' são considerados indivíduos que foram/são atravessados/interpelados por diversos e distintos discursos que os constituem - como sujeitos - a partir de aspectos culturais.

A partir dessa lógica, pode-se dizer que, atualmente, os indivíduos, sejam eles fumantes ou não, são interpelados por inúmeros discursos que produzem diferentes posições de sujeito em relação ao cigarro e cabe comentar que são essas posições de sujeito que consequentemente definem, também, as condições de permanência em determinados espaços. É possível afirmar-se que esses discursos, que moldam os sujeitos, podem ser considerados poderosos, pois geralmente prevalecem os discursos dos indivíduos que detêm o poder. Assim, cada sociedade tem sua própria "política geral da verdade". (FOUCAULT, 2005).

Nesse sentido, é oportuno mencionar que os indivíduos que formam a sociedade são interpelados por diversos discursos, entre eles aqueles provenientes da área da Saúde que circulam, principalmente, através dos meios de comunicação e das diversas ações de conscientização promovidas por setores públicos e privados. Tais discursos pregam imperativos da saúde que são preconizados pela promoção da saúde, tanto em relação à esfera pública quanto no que se refere à esfera privada, ou seja, esses discursos consideram a saúde não apenas como algo referente aos sujeitos propriamente ditos e suas práticas individuais, mas aos sujeitos enquanto pertencentes a grupos sociais (CASTIEL; DIAZ, 2007).

Assim, os discursos de promoção da saúde, principalmente aqueles promovidos por órgãos governamentais instituem, através de suas mensagens, algumas normas relacionadas aos diferentes estilos de vida, uma vez que criam posições de sujeitos que são oferecidas como 'as melhores' a serem ocupadas/seguidas. No caso daqueles que 
não seguem 'a verdade' estipulada por tais discursos, essas representações tendem a ser negativas e diretamente associadas a dados comportamentos de risco. Nesse sentido, Lupton (2000), ao refletir sobre os discursos de saúde pública relacionados ao fumo e ao álcool, afirma que as verdades instituídas pelos discursos da promoção da saúde representam tanto o consumo do cigarro quanto o do álcool como problemas e atividades de risco que precisam ser combatidas em favor da saúde dos demais pertencentes ao grupo.

É interessante mencionar, portanto, que as questões discutidas até agora - artefatos culturais, discursos, posições de sujeito, entre outras - tornam-se referenciais para o campo da Geografia pela possibilidade de associá-las a outros conceitos operacionais e, a partir disso, serem desenvolvidas análises espaciais de modo a considerar a complexidade das relações de poder que dão origem, entre outras coisas, aos territórios urbanos e/ ou, conforme denominado por Costa (2008), às microterritorialidades urbanas.

\section{AS ESTRATÉGIAS DE INSERÇÃO/ACEITAÇÃO SOCIOESPACIAL DO FUMANTE 'ATENCIOSO’}

Após serem apresentadas algumas direções sobre o campo dos Estudos Culturais, reforça-se o fato de que muitas informações sobre o cigarro e sobre os fumantes são produzidas na área da Saúde. Porém, é necessário que os geógrafos investiguem os impactos sociais e espaciais que as políticas de combate ao fumo estabelecem sobre a população. (POLAND et al., 2010). Sobre isso, Darsie (2006) e Poland et al. (2006) argumentam que, a priori, pode ser dito que os discursos, principalmente, aqueles oriundos dos estudos em saúde têm influenciado a criação de uma gama de estratégias e de leis que contribuem para a instalação de avisos e advertências em relação ao cigarro bem como a delimitação e marcação de áreas nas quais são estipuladas a permissão ou a proibição do ato de fumar e, devido a isso, de certo modo, a permanência ou não dos sujeitos fumantes.

Tais estratégias podem ser consideradas Pedagogias Culturais ${ }^{1}$, ou seja, aquelas pedagogias que não se estabelecem na escola, mas que ampliam as instâncias educativas para fora dos ambientes educacionais, podendo ser considerados os diversos artefatos culturais que se encontram articulados à sociedade. Assim, maneiras corretas ou 'menos prejudiciais' de ser fumante são definidas e incorporadas aos hábitos cotidianos de diferentes sujeitos.

Nessa direção, Poland e Fisher (2008) afirmam que a vigilância relacionada ao cumprimento dessas normas não é feita, necessariamente, por autoridades relacionadas ao poder público, mas sim pela própria população que, engajada pelos discursos da saúde, toma para si a responsabilidade de controlar o comportamento dos fumantes quando

1 Santos (2007) salienta que no campo dos Estudos Culturais - em especial aqueles realizados no âmbito dos Programas de Pós-Graduação em Educação da UFRGS e da ULBRA - têm sido realizados estudos sobre as mais diferentes temáticas, entre elas, os filmes de Hollywood, o corpo, a geografia, a biologia e a genética. Para o autor, essa diversidade de temáticas pode ser analisada a partir desse campo como Pedagogias Culturais. 
localizados no espaço público. Tendo em vista essa situação, é possível afirmar que se torna aceitável e recomendado avaliar e, caso necessário, chamar a atenção de fumantes que tentem fumar em espaços que deveriam estar 'livres' da fumaça dos cigarros. $\mathrm{Na}$ visão dos autores, esse controle se manifesta a partir de ameaças relacionadas à vergonha e ao embaraço que emergem em decorrência das normas sociais e das expectativas quanto ao comportamento público aceitável.

De certo modo, essa vigilância deve servir como um controle relacionado a comportamentos impróprios, atrelados ao cigarro, que podem vir a prejudicar a saúde e o bem-estar dos demais componentes do grupo ou então, em um nível mais amplo, de todas as pessoas que se encontram no mesmo ambiente em que estão os fumantes. Considerando isso, as autoridades formais seriam o último recurso para o reforço do cumprimento das normas nos casos em que estratégias mais sutis - articuladas por indivíduos comuns - sejam ineficientes. Nesse contexto, obediência, tanto às regras da lei quanto às sanções sociais informais, transforma-se em demonstração de competência social por parte do sujeito fumante.

Sobre isso é interessante ser comentado que a população se encontra engendrada a um regime de verdade, ou seja, a um contexto em que a verdade estipulada - contato com o cigarro ou com a fumaça do cigarro mata - constrange a todos e faz com que concordem em seguir as normas determinadas pela própria verdade (FOUCAULT, 2010). Sobre esse constrangimento é importante ressaltar que o autor explica que não se trata de um constrangimento no sentido de vergonha ou outra explicação que possa ser negativa, mas de uma adesão à verdade, situação que provoca, segundo ele, a emergência da ideia de governamentalidade. Como consequência de um regime de verdade que produz obediência a partir dos riscos relacionados ao cigarro, estratégias de governamento ajudam a constituir novas formas de se relacionar com os demais sujeitos no espaço público.

Essas questões se tornam mais explícitas, principalmente, quando um fumante acende um cigarro em espaços compartilhados com pessoas que não fumam. Muitas vezes, essa ação pode gerar um clima de desconforto por parte dos não fumantes e constrangimento em relação ao fumante. Por causa de ocasiões como essas é que fumantes frequentemente são vistos pelos outros e por si próprios como infratores das boas normas de convivência social e como não merecedores do 'visto' de permanência em determinados espaços.

É possível dizer ainda que mesmo o fumante que se afasta ou se esconde dos outros indivíduos para fumar, o qual podemos chamar de fumante cuidadoso, prevenido ou, como denomina Poland (2000), "considerate smoker" - termo traduzido por Darsie (2006) como 'fumante atencioso' - por não pretender incomodar ninguém ou ser julgado pelo seu ato, pode ser considerado um sujeito inconveniente, pois, no limite, pode-se afirmar que o cheiro da fumaça do cigarro pode 'contaminar' espaços onde o ato de fumar é proibido. Diante dessa situação, é interessante citar novamente Poland (ibidem), que baseado em entrevistas qualitativas, realizadas com fumantes, buscou levantar algumas questões referentes aos comportamentos e à consideração desses sujeitos no que diz respeito ao convívio com não fumantes em determinados espaços. 
Para o autor, a consideração por parte dos fumantes para com os não fumantes é constituída por comportamentos como não fumar na presença de não fumantes (sempre, ou em situações específicas, por exemplo, na presença de crianças ou pessoas com problemas respiratórios), encontrar maneiras de conter, minimizar ou 'gerenciar' a fumaça dos cigarros (soprar a fumaça para cima ou para longe dos outros, segurar o cigarro longe daqueles que estão sentados por perto, ficar perto de uma janela, sentar no canto de uma área designada para fumantes etc), respeitar espaços designados (sinalizados pela presença de sinais) e espaços cujos donos são não fumantes (seus carros/casas, aonde seus desejos devem prevalecer), e responder amigavelmente (sincera e educadamente) aos pedidos de não fumar. Darsie (2006) complementa essas observações ao dizer que tais estratégias podem ser adotadas, inclusive, em momentos em que não fumantes se inserem em áreas destinadas aos fumantes, fato que reflete a potência dos discursos que envolvem o combate ao fumo e a promoção da saúde nos dias de hoje.

A partir das considerações tecidas até aqui, é possível afirmar que devido aos discursos da saúde e à noção de 'fumante atencioso', acabam sendo delimitadas, no espaço público, áreas destinadas aos não fumantes a partir do uso de sinalizações (cartazes, adesivos etc.) que operam, metaforicamente, como barreiras que visam bloquear a fumaça produzida pelos cigarros dos fumantes. Essas áreas são formadas a partir de relações que envolvem questões relacionadas ao poder, tanto por parte do Estado que estipula as leis quanto pela população que, como já revelado, opera na vigilância relacionada ao seu cumprimento.

Nesse sentido, essas áreas podem ser consideradas como territórios formados para/ pelos não fumantes, o que ocasiona, em primeiro lugar, na perspectiva em que se insere esse trabalho, a possibilidade de um deslocamento conceitual. No lugar de uma abordagem que considere áreas de fumantes e de não fumantes, configura-se uma discussão que envolve, em princípio, territórios de fumantes e de não fumantes.

\section{A EMERGÊNCIA DOS TERRITÓRIOS DE NÃO FUMANTES E A DELIMITA- ÇÃO DO ESPAÇO PÚBLICO}

O conceito de território é central para a Geografia, pois diz respeito à espacialidade humana. Esse conceito apresenta relevância, também, em áreas diversas como a Ciência Política, a Economia, a Sociologia, entre outras. (HAESBAERT, 2004). Falar sobre territórios pressupõe considerar espaços que são tomados e, a partir da delimitação de suas extensões, controlados conforme as normas estipuladas por seus 'proprietários'. Andrade (2002) esclarece que o conceito de território não deve ser confundido com a ideia de espaço, pois o território é tomado por noções de gestão de uma área definida. Portanto, para o autor, a ideia de território deve ser invariavelmente ligada à noção de poder. Já Geiger (2002) descreve território como sendo uma extensão de terra, na qual se incluem relações de poder ou posse de determinado grupo social.

Suertegaray (2001) indica que o conceito de território, na Geografia, já foi definido a partir do solo enquanto espaço ocupado por uma determinada sociedade. Para ela, essa 
concepção clássica de território, utilizada por autores como Frederico Ratzel, diz respeito principalmente ao domínio de uma determinada área, possibilitando uma perspectiva de análise centrada na identidade nacional. Nesse sentido é possível se pensar que o território foi entendido como espaço absoluto, no qual seus limites físicos definiriam uma unidade de identificação nacional ligada, entre outras coisas, aos recursos naturais.

Para Santos (2002), o território, no passado, servia como suporte para o estabelecimento do Estado-nação que ao mesmo tempo o moldava e o protegia de invasões e transformações. Assim, para garantir a segurança dos seus territórios, os Estados trataram de delimitar fronteiras e protegê-las por intermédio da força armada. Heidrich (1998), ao se referir à constituição do território, nos diz que a diferenciação do espaço em âmbito histórico tem início a partir da delimitação do mesmo, isto é, por sua apropriação como território, em parte determinado pela necessidade e posse de recursos naturais para a conquista das condições de sobrevivência e, por outro lado, por sua ocupação física como habitat. Neste instante, a defesa territorial é exercida diretamente pelos membros da coletividade que nele habitam.

Sobre essa ideia, de um território no qual o sentimento de nacionalismo pode vir a potencializar a defesa de um espaço protegido por uma comunidade de iguais, Anderson (2008) propõe a noção de 'comunidades imaginadas', ou seja, discute a forma como os sujeitos pertencentes a determinados territórios acreditam que os demais sujeitos que vivem dentro das fronteiras estabelecidas compartilhem os mesmos ideais nacionalistas, mesmo que esses sujeitos nunca venham a conhecer uns aos outros. Portanto, o único elo que garante certa homogeneidade, no que diz respeito à identidade nacional, para Anderson (ibidem), efetivamente, é a imaginação de que todos seriam iguais no que se refere ao sentimento de nacionalismo, fato que ajudaria a manter a integridade do território nacional.

Haesbaert (op.cit.), no entanto, refere que o significado de território, no campo da Geografia, tem sido alterado com o passar dos anos. O território contemporâneo, conforme definição de Gomes (2008), não é apenas um espaço natural demarcado e gerenciado por governantes, mas é um espaço sobre o qual o controle exercido sobre as pessoas se dá a partir do poder, ou seja, a partir de determinados sujeitos sobre outros. Assim, pode ser entendido que para a constituição de territórios, é necessário que existam tanto o espaço quanto às relações sociais (ancoradas nas relações de poder) que serão estabelecidas sobre ele.

Segundo Gomes (2008):

[...] o território se define a partir do poder que uma pessoa ou um grupo alcança impor sobre outros indivíduos, isso significa que o titular ou os titulares desse domínio logram êxito na ação de influenciar ou controlar outras pessoas através de uma estratégia verdadeiramente espacial. (p. 37-38)

Tendo em vista as palavras do autor, torna-se relevante mencionar a perspectiva de poder estabelecida por Michel Foucault (1998). Para o filósofo francês, o poder opera de forma microfísica em toda a sociedade. Não se trata de um poder vertical, soberano, 
exercido pelo Estado, mas sim de uma malha de relações que se desenvolve em nível horizontal a partir de micropoderes relacionados ao saber, ou seja, ao domínio de conhecimentos sobre os quais se estabelecem as relações interpessoais.

Mesmo assim, é relevante ser mencionado que, no caso das ações de combate ao fumo, podem ser consideradas tanto as estratégias de vigilância, estabelecidas pelos sujeitos, quanto às leis que envolvem o tema. É relevante ser frisado que ambas as instâncias agem de forma articulada e complementar. As leis relacionadas ao cigarro e aos fumantes agem no sentido de determinarem os limites territoriais. É a materialidade dessas normas, representada pelas proibições, sinalizações e, até mesmo, pelas multas sobre os estabelecimentos que não as cumprem, que constitui os territórios de não fumantes.

É possível afirmar que o espaço público tem se tornado, atualmente, cada vez mais controlado e vigiado por leis e por autoridades cujo objetivo é diminuir/extinguir o cigarro. É possível se dizer ainda que, de acordo com tal lógica, as áreas para fumantes tendem a se tornarem extintas, mesmo em espaços abertos. No entanto, conforme será abordado, novas possibilidades de agrupamentos de sujeitos fumantes emergem no âmbito do espaço público, como forma de resistência às leis vigentes, e isso pode ser considerado relevante para as análises geográficas, visto que representa a configuração de microterritórios de resistência relacionados ao fumo.

\section{MICROTERRITORIALIZAÇÕES RAREFEITAS: OS MICROAGREGADOS SOCIAIS DE FUMANTES NO ESPAÇO PÚBLICO}

Conforme argumentação explicitada anteriormente, as leis que se relacionam ao espaço e ao combate ao fumo estabelecem dinâmicas territoriais definidas, principalmente, por limites físicos que são determinados com o apoio do Estado em prol da saúde dos indivíduos. No entanto, conforme já mencionado em outro momento, pode ser pensado que as relações de poder em uma sociedade se estabelecem de forma microfísica, fato que oportuniza a emergência de relações complexas que se projetam no espaço e, a partir disso, constituem múltiplos territórios dentro do espaço urbano.

Suertegaray (2001) afirma que o território deva ser considerado como um campo de forças que ocorrem devido a sua complexidade. A ideia de complexidade se constituiu a partir do entendimento de que as relações humanas, bem como as relações de poder, estão no centro de determinadas situações - em razão disso, surge a impossibilidade de se generalizar e de se prever os acontecimentos imersos nos territórios. Para Almeida (2004), a complexidade é algo imprevisível, pois os fenômenos complexos, que abrangem a condição humana, o sujeito, a sociedade, a educação, a política, a cultura são instáveis. Segundo a autora, a complexidade não é regida por leis universais e imutáveis, o que ocasiona a incerteza no que diz respeito a ela, nesse caso, territorial. Segundo Roux (2004), os complexos se constroem e se mantêm através das informações que interpelam os sujeitos participantes desses territórios complexos e os reorganizam constantemente, tornado-os permanentemente inacabados. Para Suertegaray (2004), “o pensamento complexo implica em reconhecer a dialética, a contradição e as oposições que fazem progredir o pensamento, mas também as ações" (p.193). 
Assim, considerando a impossibilidade de se estabelecerem territórios homogêneos e ordenados, Haesbaert (2004) argumenta que as territorialidades contíguas e contínuas estariam cedendo lugar, hoje em dia, às múltiplas territorialidades, ou seja, à possibilidade de os sujeitos transitarem por entre diferentes territórios de acordo com suas necessidades e vontades. Em diferentes momentos, sujeitos que podem ser completamente desconhecidos acabam por se juntar em determinados lugares do espaço, motivados por identidades comuns ao grupo. Dentre as diferentes identidades pelas quais esses sujeitos são constituídos, fazendo emergir, dessa forma, as chamadas territorializações.

De acordo com Costa $(2002,2008)$, microterritorializações são formadas no espaço urbano por um conjunto de ações e práticas que definem os microagregados socioespaciais a partir dos processos identificatórios pessoais, ou pela procura de relações afetivas, estéticas e comportamentais, as quais fazem parte de seus desejos e prioridades emocionais vinculados à identidade pessoal. Conforme o autor, torna-se possível a observação de indivíduos que atuam sobre o espaço no sentido de se apropriarem dele a partir de ações com objetivos relacionais. Assim, as territorializações são construídas por sujeitos que expressam ações objetivadas, ou seja, a apropriação espacial devido a uma intenção relacional. Haesbaert (2004) argumenta que, ao se falar em territorialização, é relevante levarem-se em conta as ações dos sujeitos que promovem a atividade relacional e seu processo de segregação e apropriação espacial, assim como a própria materialidade da territorialização, como localização, agentes empreendedores, ambiente estético, ação da mídia que tenta atrair certo público etc.

É importante considerar que o pressuposto primeiro de toda a territorialização é a formação de identidades espaciais. Primeiramente, os sujeitos precisam sentir-se confortáveis e protegidos nos espaços onde convivem, com base em aspectos relacionais entre os frequentadores de tais espaços. Assim, a união do agregado territorial é estabelecida em um primeiro momento por um interesse individual dos sujeitos e das sensações em relação aos aspectos estéticos e comportamentais dos espaços. Num segundo momento, o agregado territorial condiciona a participação de seus elementos, selecionando e impondo regras de comportamento a cada um (COSTA, 2002).

A partir disso, de acordo com os autores, a formação de territorializações e microterritorializações pode ser compreendida como agregados/microagregados relacionais espaciais. Elas são conformadas por materialidades, ou seja, partes do espaço e por diferentes posições de sujeitos, sendo essas estabelecidas a partir das diferentes ações dos sujeitos que promovem processos de identificação com o espaço, segregando-se e sendo segregados em relação a outros agentes, estabelecendo assim fronteiras de convivência, como, por exemplo, os microagregados de fumantes que se contrapõem aos territórios de não fumantes.

É possível considerar, em relação a isso, de acordo com os exemplos que foram apresentados e com as leis relacionadas ao fumo, que o fumante, nos dias de hoje, é o sujeito que se diferencia, sendo considerado, muitas vezes, um indivíduo inconveniente.

Para Gomes (2002): 
O território próprio ao grupo é concebido como um terreno onde as regras que fundam a identidade gozam de uma absoluta e indiscutível validade. A predominância do nível coletivo é total, e a oposição e a diferenciação são estabelecidas em relação à figura de um outro que é exterior ao grupo. (p.180).

A partir disso, é possível argumentar que os fumantes estabelecem microterritorializações em lugares onde o fumo é permitido - cada vez mais escassos -, ou nas margens dos limites impostos pelos territórios de não fumantes. Isso significa que ao serem apartados de determinadas áreas, os fumantes se aglomeram, muitas vezes, nas proximidades dessas mesmas áreas para fumar, instituindo assim, posturas de resistência.

Portanto, é interessante considerar que espaços como, por exemplo, aqueles próximos às portas dos shopping centers, servem como espaços promotores de microterritorializações de fumantes. Quando lembrada a época em que o fumo era permitido no interior desses centros de compras, retoma-se a ideia de que as portas desses estabelecimentos serviam apenas para a entrada e saída de seus visitantes, porém, nos dias de hoje, os espaços externos a esses 'territórios de não fumantes' reúnem sujeitos fumantes que os utilizam como 'salas de fumantes'. Esses microagregados sociais, relacionados ao hábito de fumar, podem ser considerados bastante significativos, visto que têm chamado a atenção dos administradores desses estabelecimentos. Isso pode ser exemplificado pelos processos ligados à criação e construção de ambientes mais agradáveis - com bancos, cinzeiros e jardins - seja como forma de proporcionar certo conforto aos clientes fumantes, seja para amenizar o impacto estético que o grupo de fumantes pode causar.

Contudo, as microterritorializações de fumantes estabelecem um elemento paradoxal aos preceitos da saúde e às leis que acabam por delimitar os grandes territórios urbanos de não fumantes. Discussões sobre os agregados sociais compostos por fumantes servem como provocação no intuito de gerar reflexões sobre a emergência daquilo que Darsie (2006) denominou como territórios de exclusão, ao considerar que determinados sujeitos têm sido apartados de determinadas parcelas do espaço público em decorrência daquilo que Lupton (2000) chama de 'práticas alternativas do eu', ou seja, aquelas práticas que contrariam os discursos vigentes como, por exemplo, o hábito de fumar.

Portanto, considerar a existência desses agregados sociais significa operar no sentido de analisar as formas como os discursos da saúde, principalmente aqueles ligados à promoção da saúde, atravessam e (re)modelam aspectos culturais relevantes de nossa sociedade. Além disso, oportuniza a emergência de discussões relacionadas ao espaço e às relações sociais que lhe conferem sentidos diversos.

\section{CONSIDERAÇÕES FINAIS}

De acordo com o que foi apresentado, é possível se pensar que os impactos socioespaciais causados pelos discursos da saúde, em especial pelas ações de combate ao fumo, são relevantes para os geógrafos. Essa relevância se justifica pelo fato de indicarem novas possibilidades analíticas no que se refere à disposição da população e à criação de áreas que lhe impõem limites comportamentais relacionados ao hábito de fumar. 
Nesse sentido, um dos caminhos possíveis para o desenvolvimento de uma abordagem sobre a temática proposta é o campo dos Estudos Culturais. Essa escolha teórica e metodológica proporciona a aproximação e articulação de diferentes áreas à Geografia, ampliando, assim, as perspectivas pelas quais o tema pode ser analisado.

Assim, pode ser entendido que o espaço público urbano se encontra fragmentado por diversos territórios compostos por sujeitos que se agregam de acordo com traços identitários comuns. Entre esses sujeitos, encontram-se os fumantes que fazem emergir microterritorializações, pautadas no hábito de fumar, como resultado de ações de resistência - conscientes ou não - em relação a um regime de verdade que institui a proibição do fumo na maior parte do espaço público urbano. Essa fragmentação do espaço se estabelece em decorrência das relações microfísicas de poder que, apoiadas pelas normas sancionadas pelo Estado, projetam sobre a população, mesmo que de forma sutil, a responsabilidade relacionada ao governo para garantir o cumprimento delas.

Portanto, ao se analisarem aspectos relacionados ao cigarro, aos fumantes e ao espaço, pode ser entendido que as microterritorializações promovidas por sujeitos fumantes são resultado da delimitação das áreas onde o fumo é proibido, associada à vigilância exercida pelos não fumantes que, apoiados pela legislação vigente, impõem normas de permanência em determinados momentos e parcelas do espaço público.

\section{REFERÊNCIAS}

ALMEIDA, Maria da Conceição de. Mapa inacabado da complexidade. In: SILVA, Aldo Aluísio Dantas da; GALENO, Alex (Orgs.). Geografia ciência dos complexus: ensaios transdisciplinares. Porto Alegre: Sulina, 2004, p. 09-41.

ANDERSON, Benedict. Comunidades imaginadas. Tradução Denise Bottman. São Paulo: Companhia das Letras, 2008.

ANDRADE, Manuel Correia de. Territorialidades, desterritorialidades, novas territorialidades: os limites do poder nacional e do poder local. In: SANTOS, Milton; SOUZA, M. A. SILVEIRA, M. L. (Orgs.). Territórios: globalização e fragmentação. São Paulo: Hucitec, 2002, p. 213-220.

CASTIEL, Luis David, DIAZ, Carlos A. D. A saúde persecutória: os limites da responsabilidade. Rio de Janeiro: Editora Fiocruz, 2007.

COSTA, Benhur Pinós da. Territorializações: ações de agregados sociais. In: Caesura - Revista Crítica de Ciências Sociais e Humanas, Canoas, n. 21, p. 67-72, 2002.

. Microterritorializações urbanas: análise das microapropriações espaciais de agregados sociais de indivíduos same sex oriented em Porto Alegre/RS. In: HEIDRICH, Álvaro L. et al. (Orgs.). A emergência da multiterritorialidade: ressignificação da relação do humano com o espaço. Porto Alegre: UFRGS Editora / Editora da ULBRA, 2008, p. 177- 200.

DARSIE, Camilo. Territórios de exclusão: educação, saúde e representações de fumantes no espaço público. Canoas: ULBRA, 2006. Dissertação (Mestrado em Educação). Faculdade de Educação. Programa de Pós-graduação em Educação, Universidade Luterana do Brasil, 2006.

DU GAY, Paul. Doing cultural studies: the story of the Sony walkman. (Praticando estudos culturais: a história do walkman da Sony. Trad. Leandro Guimarães, Marília Braun e Maria Isabel Bujes). London: Sage Publications/ The Open University, 1997. 
ESCOSTEGUY, Ana Carolina. Estudos culturais: uma introdução. In: SILVA, Tadeu T. da (Org.). O que é afinal estudos culturais? Belo Horizonte: Autêntica, 2000, p. 37-129.

FAIRCLOUGH, Norman. Discurso e mudança social. Brasília: Editora da Universidade de Brasília, 2001. FOUCAULT, Michel. Microfísica do poder. Rio de Janeiro: Edições Graal, 1998.

. Vigiar e punir: nascimento da prisão. Trad. Raquel Ramalhete Petrópolis: Rio de Janeiro: Editora Vozes, 2005.

Do governo dos vivos: curso no Collége de France, 1979-1980. Trad. Nildo Avelino. Rio de Janeiro: Achiamé, 2010.

GEIGER, Pedro P. Des-territorialização e espacialização In: SANTOS, Milton; SOUZA, Maria Adélia; SILVEIRA, Maria Laura (Orgs.). Território: globalização e fragmentação. São Paulo: Hucitec, 2002. p. 233246.

GOMES, Paulo César da Costa. A condição urbana: ensaios de geopolítica da cidade. Rio de Janeiro: Bertrand, 2002.

Sobre territórios, escalas e responsabilidade. In: HEIDRICH, Álvaro L. et al. (Orgs.). A emergência da multiterritorialidade: ressignificação da relação do humano com o espaço. Porto Alegre: UFRGS Editora / Editora da ULBRA, 2008. p. 37-46.

HALL, Stuart. Significação, representação e ideologia: Althusser e os debates pós-estruturalistas. In: SOVIK, Liv. (Org.). Da diáspora: identidades e mediações culturais. Trad. Adelaine La Guardia Resende... [et al.]. Belo Horizonte: Editora UFMG; Brasília: Representações da UNESCO no Brasil, 2003, p. 91-114.

HAESBAERT, Rogério. Concepções de território para entender a desterritorialização. In: Território, territórios. Niterói: PPGEO-UFF/AGB-Niterói, RJ, 2002. p. 17-38.

O mito da desterritorialização: do "fim dos territórios" à multiterritorialidade. Rio de Janeiro: Bertrand Brasil, 2004.

HEIDRICH, Álvaro Luiz. Fundamentos da formação do território moderno. Boletim Gaúcho de Geografia, n. 23, AGB - Seção Porto Alegre, 1998.

JOHNSON, Richard. O que é afinal estudos culturais? In: SILVA, Tadeu T. da (Org.). O que é afinal estudos culturais? Belo Horizonte: Autêntica, 2000.

LUPTON, Deborah. Corpos, prazeres e práticas do eu. In: Educação e Realidade. v.25, n.2, p. 15-48. Porto Alegre, jul./dez. 2000.

POLAND, Blake D. The 'considerate' smoker in public space: the micro-politics and political economy of 'doing the right thing'. Health Place - PubMed/Medline, v. 6, n. 1, p. 1-14, 2000.

POLAND, Blake D, et al. The social context of smoking: the next frontier in tobacco control? Tobacco Control, v. 15, p.59-73, 2006.

POLAND, Blake D; FISCHER, Benedikt. Exclusion, 'risk', and social control: reflections on community policing and public health. Geoforum, v.29, n.2, p. 187-197, 2008.

.; HAINES, R. J; OLIFFE, J. L.; BOTTORFF, J. L. 'The missing picture': tobacco use through the eyes of smokers. Tobacco Control, v.19, p.206-212, 2010.

ROUX, Michel. O re-encantamento do território. In: SILVA, Aldo Aluísio Dantas da; GALENO, Alex (Orgs.). Geografia ciência dos complexus: ensaios transdisciplinares. Porto Alegre: Sulina, 2004. p. 42-66.

SANTOS, Luis Henrique Sacchi dos. O corpo que pulsa na escola e fora dela. In: WORTMANN, Maria Lúcia et al. (Orgs.). Ensaios em estudos culturais educação e ciências: a produção cultural do corpo, da natureza, da ciência e da tecnologia. Porto Alegre: Editora da UFRGS, 2007. p.131-146.

SANTOS, Milton. O retorno do território. In: ; SOUZA, Maria Adélia; SILVEIRA, Maria Laura (Orgs.). Territórios: globalização e fragmentação. São Paulo: Hucitec, 2002. p. 11-14.

SILVA, Tomaz Tadeu da. Teoria cultural e educação: um vocabulário crítico. Belo Horizonte: Autêntica, 2000. 
SUERTEGARAY, Dirce Maria. Espaço geográfico uno e múltiplo. Revista de Geografia y Ciencias Sociales, n. 93, jul., 2001.

. Ambiência e pensamento complexo: resignific(ação) da Geografia. In: SILVA, Aldo Aluísio Dantas da e GALENO, Alex (Orgs.). Geografia ciência dos complexus: ensaios transdisciplinares. Porto Alegre: Sulina, 2004. p.181-208.

Recebido em 16/01/2012

Aceito para publicação em 20/02/2012 